\title{
The Internet's impact on incumbent media firms: a management perspective
}

\author{
Lucy Küng
}

This article explores the impact of the Internet on incumbent media firms from the perspective of management theory. It examines how with the arrival of the Internet media firms have become exposed to a strategically demanding environment characterised by high levels of uncertainty, not least surrounding the fundamental operating model for online media. One result has been a shift in organisational priorities within media firms, specifically in favour of business and commercial issues at the expense of cultural and intellectual concerns, a development this article terms 'commercialisation'. The article finds that this process can be observed at firm and at product level. The article concludes by suggesting that the emergence of the Internet has served to reinforce commercialisation processes that were already present in the media industry. It predicts that while the pace of development in the online field may have slowed, the uncertainties intrinsic to its strategic context and the challenges associated with its management mean that commercialisation pressures are likely to persist.

\section{Introduction}

The emergence of the Internet has heralded a new era for incumbent media firms. From a management perspective one of the most noteworthy aspects of this is an increasing emphasis on financial and commercial concerns at the expense of broader social, intellectual or cultural ones, a development which is evident at both firm and product (content) level. Adopting the standpoint of management theory this article explores these changes.

The St. Gallen Management Model provides the broad structure whereby developments are analysed at three levels: the strategic context or environment of media organisations, the media firm itself, and the core product of the media organisation, media content. In terms of media firms, the article adopts the standpoint of incumbent media organisations - that is existing media players with their origins in the traditional mass media, as opposed to 'insurgent' new media firms.

The pace of change in the new media arena, the significant intrinsic differences in national media systems, and the sheer volume of variables at work in the competitive environment mean that this article can only offer an idealised typology of developments in the broadest sense. The speed and scope of change creates terminological problems also. To date the terms 'new media' and 'new economy', while frequently used, particularly by practitioners, are ambiguous at best. Unfortunately they can be taken to imply that that which went before was 'old' and by extension antiquated and out of date. This is not the case with this article where 'old' is used in the sense of 'existing' or 'traditional' and does not carry implicit negative connotations. Similarly 'new' is used in the sense of 'emergent' and does not per se imply 'superior'.

\section{A changing strategic context}

The online media owe their existence to the emergence of the Internet. Around the world, uptake of the Internet by businesses and consumers has been extraordinary. It is 
the world's fastest growing communications medium (US Department of Commerce, 1998 ) and as of June 2000 over 300 million people worldwide have online access ${ }^{1}$. From an environmental perspective the Internet can be viewed as one - arguably dominant element in a complex amalgam of entwined technological and political change commonly termed 'convergence', a phenomenon this article understands as the gradual erosion of structural barriers between the media, telecommunications and information technology industries and markets (Fidler, 1997; Chakravarthy, 1997; Bradley and Nolan, 1998; Collis et al., 1997).

The emergence of the Internet placed incumbents under a pressure to embrace online ${ }^{2}$ media that with the benefit of hindsight appears extreme. This stemmed from many directions, from many different stakeholder groups, at once. Arguably at the root of this sense of urgency was the financial markets' enthusiasm for the new media sector. From the mid-1990s to early 2000 extraordinarily high valuations were awarded to businesses that sought to exploit the potential of the Internet. Those concerned with the provision of content were some of the most highly rated of all (Gemini, undated). This led in turn to pressure from shareholders and key executives who wanted to participate in this bonanza, and was further amplified by a widely held view that the online world was characterised by powerful order of entry advantages (i. e. that the 'first mover' in the Internet arena would establish an unassailable beachhead, and that laggards would be severely disadvantaged) (Helmore, 2000). A further imperative came from consumers, who had adopted the Internet far more speedily than had been anticipated (although they were in general attracted by communications-based 'content' such as chat and email rather than 'traditional' forms of content available over the Internet).

As a result of these pressures Internet-related activities became a strategic priority for incumbent media firms and many made very significant financial commitments to the field $^{3}$ (Hatlestad, 2000; Deutsche Bank, 1999; Harding, 2000a, 2000b; Ewing, 2000). They moved aggressively online and in consequence were exposed to a very different strategic environment. Environmental change is not new to the media industry - from the 1980s onwards the sector had undergone a series of far-reaching changes. But while these changes brought with them at times dramatic consequences, they represented in general incremental, albeit one off, alterations to the status quo - a gradual liberalisation of markets, a gradual introduction of new transmission technologies for existing categories of media products, a gradual shift from collective to individual payment systems, a gradual adoption of PC-based production methods and so on.

Through their engagement with the Internet, incumbents came into contact with an 'emergent' strategic context (Porter, 1980), very different to the 'mature' one they were accustomed to. Mature contexts are characterised by slow growth, intense competition between a known group of well-entrenched players and knowledgeable customers. Emergent environments, such as those surrounding the high tech and Internet sectors,

1 Figures from Screen Digest, June 2000: 191.

2 Online media are defined as services, interactions or transactions that require continuous connection to an electronic communications network (Fidler, 1997). The electronic network referred to in this paper is the Internet.

3 For example during the first quarter of 2000 Reuters announced it had budgeted investments of $£ 500 \mathrm{~m}$ over the next four years, Reed Elsiever $£ 600-700 \mathrm{~m}$ over the next three years, and BSkyB $£ 250 \mathrm{~m}$ over the next 18 months. All of these investment programmes have since been scaled back or cancelled. 
are dynamic 'highly competitive, high velocity' contexts (Eisenhardt and Brown, 1998) where levels of uncertainty are high. Industry boundaries are unclear, new business concepts emerge rapidly and established ones are equally easily displaced (Robins and Wiersema, 1999), technology and consumer preferences are uncertain and competition comes from many directions at once, from start-ups, from other incumbents, and from new types of substitutes.

\section{Summary 1: Changes to incumbent media firms' strategic context}

\begin{tabular}{lll}
\hline 'Traditional' media industry & & 'New media' industry \\
\hline $\begin{array}{l}\text { incremental: significant but } \\
\text { gradual, episodic change }\end{array}$ & $\begin{array}{l}\text { nature of environmental } \\
\text { change }\end{array}$ & $\begin{array}{l}\text { radical: discontinuous, } \\
\text { fast-moving and ongoing }\end{array}$ \\
\hline $\begin{array}{l}\text { mature: slow growth, intense } \\
\text { competition from entrenched } \\
\text { players }\end{array}$ & $\begin{array}{l}\text { nature of strategic } \\
\text { environment }\end{array}$ & $\begin{array}{l}\text { emergent: technological } \\
\text { uncertainty, competition } \\
\text { from new players, } \\
\text { short-term planning horizons }\end{array}$ \\
\hline stable, static, knowledgeable & nature of markets & turbulent, first-time \\
consumers & & buyer markets \\
\hline
\end{tabular}

\section{Changing management priorities}

Emergent contexts present a complex management challenge, particularly for established players 'encumbered' by fixed assets and 'legacy' systems and processes. They demand high levels of management attention, in turn forcing a preoccupation with matters of management and business from all senior level employees whether they occupy management or creative functions. When the competitive arena is constantly evolving and unpredictable, the nature of strategic activity changes. In theoretical terms attention shifts from the 'content' of strategy to the 'process' by which it is developed and implemented. Rather than develop detailed strategies based on extensive competitive analysis, management must instead ensure the organisation is capable of adapting in step with evolving markets, through providing scope for autonomous action, by establishing joint ventures and alliances and acquiring new capabilities. This means they must not only be creative from a product perspective but from an organisational one too.

The increasing complexity of the management task inevitably deflects attention away from traditional product-related concerns. In the case of online media, this was compounded by the financial uncertainties present in the online sector as a whole. These centred on the issue of 'business model'. This ubiquitous and loosely-defined term refers to how a company does business and generates revenue (Porter, 2001). The 'default' business model for traditional media businesses (with the exception of public service broadcasters) has been that they receive revenue in return for delivering audiences to advertisers, those audiences having been attracted by the content media products 'contain'. Characteristics of this model are that it has a significant component of indirect payment (a large proportion of costs being born by advertisers or, in the case of public service broadcasters, by public contributions) and is collective (payment models are based on aggregating the largest possible number of consumers - a mass audience) and based on standardised products. 
In the new media field there are, theoretically, at least three options for funding online content, advertising, subscription and transaction fees, but as yet however none has proved entirely successful. It was initially assumed that a business model relying on a combination of advertising and transaction fees would evolve ${ }^{4}$. This proved not to be the case and to date online advertising revenues have been modest and unreliable (Warburg Dillon Read, 2000). Similarly, subscription fees, one of the longest-established business models for offline content, have been a limited success online. The chief barrier is simply that Internet users have come to expect information for free, and appear willing to pay only for certain categories of content, for example 'adult' content (pornography), betting and gaming. Disappointment over advertising and subscription revenues led to increasing interest in the possibilities of e-commerce as a potential source of revenue. So far however e-transaction incomes have also been modest (Warburg Dillon Read, 2000).

As a result, new media divisions came to exert a disproportionately large impact on their parent organisation, in particular forcing an organisation-wide concentration on issues of funding and finance. Online media activities are expensive and in the absence of online revenues these costs must be met through cross subsidisation by offline media activities. Further, during the late 1990s and early 2000s most public media companies were seeking an early flotation of their Internet divisions as a means of capitalising on the high valuations placed on internet-related businesses and providing shares to finance growth through acquisitions and to compensate key executives. Indeed in the absence of real profits, an early IPO (initial public offering) became almost the default business model for online media businesses. This also forced a short-term financial perspective, since both the IPO process and publicly-listed status are characterised by intense attention on revenues and market share.

Summary 2: Changes to incumbents' organisational focus

\begin{tabular}{lll}
\hline 'Traditional' media firm & & 'New' media firm \\
\hline 'content' of strategy & strategy focus & 'process' of strategy \\
\hline $\begin{array}{l}\text { incremental - improvements } \\
\text { to existing products and } \\
\begin{array}{l}\text { development of new products } \\
\text { along established lines }\end{array}\end{array}$ & $\begin{array}{l}\text { focus of product } \\
\text { innovation }\end{array}$ & $\begin{array}{l}\text { new to the world } \\
\text { products and services }\end{array}$ \\
\hline $\begin{array}{l}\text { well-established, proven } \\
\text { product-focused (product } \\
\text { creativity, marketing) }\end{array}$ & business model & uncertain \\
\hline
\end{tabular}

4 See, for example, Vogel, 1999. 


\section{Changes to media content}

At the content level, a process of commercialisation can be observed in the blurring of boundaries between editorial and commercial elements and in the fact that online commercial considerations exert a far stronger influence over the nature of content displayed than in an offline environment.

Content lies at the heart of all media businesses. From a management perspective the activity of creating content ${ }^{5}$ is the sector's defining 'core competence' (Hamel and Prahalad, 1994; Kay, 1993) and the thread that connects the diverse sub-sectors ranging from scientific publishing to traffic bulletins. The so-called 'mass paradigm' has long defined the 'mass' media industries. This refers to the delivery of a universal, identical message from a powerful and centralised message source to a potentially unlimited audience. The essential model therefore is a point-to-multipoint one whereby communication is one way; the receiver of the message is not able to communicate with the sender of the message using the same media (McQuail, 1987; v. Krogh/Roos, 1986). This paradigm reflects two linked environmental phenomena prevalent during the emergence of the electronic mass media. The first, increasingly invalid in the current converging climate, was that bandwidth was scarce and needed to be rationed, and the second was a conviction that the mass media had the power to shape public attitudes. Thus the 'old' media model is predicated on a limited number of outlets, a virtually captive audience and scarcity of product in the face of mass demand (Wolf, 1999a).

The mass media model is linear and highly structured - content is either 'on' or 'off' and submitted to consumers sequentially according to pre-determined formats (DeFleur and Dennis, 1998; Makar, 2000). There is a clear distinction between content and the medium by which that content is delivered to the consumer: the medium is the carrier of the information and content is the information itself. Further, in the offline space the economic value of content is important but not all-encompassing - content is also felt to bestow important non-economic merits, for example to promote an engaged and alert democracy, to safeguard vulnerable values such as freedom of information and freedom of speech.

From the content perspective, the emergence of the Internet has given rise to an entirely new paradigm governing its form and function which reflects the intrinsic characteristics of the Internet as a communications medium. First, it is an interactive, 'pull' technology, meaning that content can be personalised and made available on demand. The underlying communication model online is that of large numbers of users engaged in interactive, unmediated, individual media experiences. Second, the medium and message are inextricably interlinked. Content (the media product being delivered in some digital form) is inseparable from the technology by which it is generated, and value to users resides as much technological aspects as in informational ones. Thus online content is simultaneously a product and a service, and the development of online content is perhaps closer to software development than journalism, characterised by trial and error, research, development and debugging. Further, whereas traditional media content

5 The term 'content', although a now ubiquitous label for the products produced by media organisations, only came to be used in that sense around 1996 (Geirland and Sonesh-Kedar, 1999). Prior to that 'content' was a somewhat specialist term for the messages conveyed by media products and generally used in connection with 'content analysis'. 
is produced by professionals for consumers, in an Internet environment the consumers' role is more pro-active - extending as far as generating content for themselves. ${ }^{6}$

As a result, rather than being an extension of the offline content paradigm, online content is a media form unto itself. Whereas offline content tends to revolve around three core elements - the 'Reithian trio' of information, education and entertainment, online content defined at its loosest comprises virtually anything that appears on a screen. Chat room conversations, dating and betting services and file sharing sites such as Napster and banner adverts all 'qualify' to those in the industry as online content. In practice this broad span of content falls into four categories:

- Information: The narrowband Internet is data-heavy, reflecting the strengths of the medium as a means of accessing, sorting and customising information, and the unimaginable range, breadth, depth and diversity (from the thousands of sources) it offers.

- Communication: One-on-one communication between users has always been an important element of online activity. Services which allow contact and interaction email, chat, interactive bulletin boards - helped fuel the early success of the medium as a whole and of leading players such as AOL (indeed in the beginning AOL offered little more than chat). Although these communications activities involve text, they are essentially extensions of oral communication.

- Community: Community sites built around common interests serve to funnel and aggregate contact activities, and since the medium's inception such communities have matured and become increasingly sophisticated, task-orientated and commercial.

- Commerce: In an online environment content and commerce are converging - media companies are becoming more commerce orientated and commerce companies are becoming concerned with developing content (Wolf, 1999b: 205; Forrester, 1999; Hatlestad, 2000). For example Amazon.com, an e-commerce site, features many elements - book reviews, synopses, extracts etc.- that are essentially content, and, conversely, content sites such as Redherring.com offer links to commercial services and embed advertising in chat rooms that take users directly to e-commerce sites.

There are a number of reasons why overtly-commercial content has become a critical element of the online content paradigm. First it simply reflects an opportunistic response to the intrinsic capabilities of Internet as a communications medium. There has always been a strong natural link between content and commerce - every purchase decision is based on information (content). On the Internet this link becomes dynamic - users can move directly from information to purchase. Further, particular types of online content - search engines, product configurators, user recommendation sites etc. can act as powerful boosts to the e-commerce process. It also reflects the fact that media companies are under pressure to exploit the link between content and commerce because of their problems financing online content.

6 Indeed one of the surprises for incumbents during the early days of the Internet was the lack of interest in 'expert' content produced by well-known brand names (for example Time Warner's Pathfinder or Microsoft's Slate) and the conversely strong attraction in user- generated content. 
Summary 3: Changes in the nature of media content

\begin{tabular}{|c|c|c|}
\hline 'Traditional' media content & & 'New' Media Content \\
\hline $\begin{array}{l}\text { information, education, } \\
\text { entertainment }\end{array}$ & core customer proposition & $\begin{array}{l}\text { synthesis of information, } \\
\text { communication, community } \\
\text { and commerce }\end{array}$ \\
\hline one-to-many, mass & $\begin{array}{l}\text { basic communication } \\
\text { paradigm }\end{array}$ & $\begin{array}{l}\text { two-way, individual, } \\
\text { interactive, on-demand }\end{array}$ \\
\hline $\begin{array}{l}\text { highly structured, linear, } \\
\text { narrative, pre-packaged, } \\
\text { transmitted according to fixed } \\
\text { schedules or formats }\end{array}$ & format & $\begin{array}{l}\text { molecular, orientated } \\
\text { around 3-D hierarchical } \\
\text { matrix }\end{array}$ \\
\hline $\begin{array}{l}\text { message not medium - the } \\
\text { medium is the carrier of the } \\
\text { message, content is the message } \\
\text { itself }\end{array}$ & $\begin{array}{l}\text { relationship between } \\
\text { content and technology }\end{array}$ & $\begin{array}{l}\text { message and medium - the } \\
\text { information engineering } \\
\text { (technology) is an intrinsic } \\
\text { element of content }\end{array}$ \\
\hline $\begin{array}{l}\text { content is the product of scarce } \\
\text { creative skills and/or trained minds }\end{array}$ & who produces content? & $\begin{array}{l}\text { anything can be content and } \\
\text { content doesn't have to be } \\
\text { produced by experts - in fact } \\
\text { many users are happiest } \\
\text { producing their own content }\end{array}$ \\
\hline
\end{tabular}

\section{Conclusions}

The emergence of the Internet has ushered in a new era for incumbent media firms, one that has served to reinforce and perhaps accelerate the commercialisation processes already at work in the media world. For media firms their involvement in the online field has necessitated a focus on financial priorities at the expense of the traditional 'non-economic' concerns as intrinsic cultural merit, social integration, democratic empowerment and public education - on the part of all employees. In terms of content, while content's strategic value may have increased (due to its role as the fuel of online business models), its intrinsic value has fallen. Symbolic, intellectual, artistic elements are still important, but they are increasingly assessed with a commercial eye. Providing access to consumers for advertisers has always been an important function of offline content, but this has been secondary to the primary goal of entertaining, educating or informing them. This is not so online where 'traditional' mass media content is a just one element of a wider paradigm which includes elements that media industry stalwarts would perhaps not normally include in a content typology.

Online content is important not because of what it is, because of any cultural, social or educational benefits it may bestow, but because of what it can do, that is, its ability to attract users. Online media products are increasingly becoming platforms for advertising and e-commerce when they are displayed on computer screens (Kehoe, 2000). As a result conceptions of what constitutes quality have also changed. In an online context attributes of 'quality' include the potential for commerce enablement, the potential for personalisation, the potential for platform neutrality, and of course 'stickiness', that is the ability to keep users on a site. 
The collapse of the dotcom sector will inevitably bring further changes for firms engaged in online media, but it is unlikely to redress the commercialisation process. Ongoing uncertainties - technological and financial - mean that management attention is likely to remain focused on matters of management and business. While the accelerating effect of the 'dotcom bubble' may have abated, the continuing absence of a default business model, the scale, speed and complexity of change, and the uncertainties intrinsic to the strategic context mean that financial and management issues will remain pressing and that commercial issues are likely to remain a paramount concern.

\section{References}

Bradley, S. P./Nolan, R. L. (eds.) (1998): Sense and respond. Capturing Value in the Network Era. Boston M. A.

Chakravarthy, B. S. (1997): A New Strategy Framework for Coping with Turbulence. In: Sloan Management Review, 38, Is 2, pp. $49-83$.

Collis, D. et al. (1997): Winners and Losers. Industry Structures in the Converging World of Telecommunications, Computing, and Entertainment. In: David B. Yoffie (Ed.): Competing in The Age of Digital Convergence. Boston M. A., pp. 159- 201

DeFleur, M. L./Dennis, E. E. (1998): Understanding Mass Communication: A Liberal Arts Perspective. Boston/New York.

Deutsche Bank (1999): The European Media Sector: A World Turned Upside Down. European Research, 11 August 1999.

Ewing, J. (2000): Can Bertelsmann take wing? In: Business Week, February 7, 2000, pp. 16 - 17.

Fidler, R. (1997): Mediamorphosis: Understanding New Media. Thousand Oaks, Calif.

Eisenhardt, K. M./Brown, S. L. (1998): Time Pacing: Competing in Markets that Won't Stand Still, in: Harvard Business Review, March-April 1998, pp. 59 - 69.

Forrester Research Inc. (1999): The Content-Commerce Collision, Cambridge M A.

Geirland, J./Sonesh-Kedar, E. (1999): Digital Babylon: How the Geeks, the Suits, and the Ponytails tried to bring Hollywood to the Internet. New York.

Gemini Consulting (undated): Net Values: Giving the Market What it Wants. In: Transformation, Issue 20, pp. $37-44$.

Harding, J. (2000a): Canal's vision for the internet age takes shape. In: Financial Times, 2 February.

Harding, J. (2000b): Reed Elsiever to invest $\$ 1.1$ bn in online services. In: Financial Times, 24 February.

Hamel, G./Prahalad, C. K. (1994): Competing for the Future. Boston.

Hatlestad, L. (2000): The new old media. In: Red Herring, March, pp. 388 - 396.

Helmore, E. (2000): What the hell is Rupert up to. In: The Guardian, 6 March.

Kay, J. (1993): Foundations of Corporate Success: How Business Strategies Add Value. Oxford.

Kehoe, L. (2000): Music bosses miss a beat. In: FT.com, May 16. Available at http://ft.com

Makar, I. (2000): To him that hath shall be given ... . Speech to 18th Annual Financial Times New Media and Broadcasting Conference, London.

McQuail, D. (1987): Mass Communication Theory: An Introduction, second Edition. Newbury Park.

McQuail, D./Euromedia Research Group (1990): Caging the Beast: Constructing a Framework for the Analysis of Media Change in Western Europe. In: European Journal of Communication, Vol.5, pp. $13-331$.

Porter, M. E. (1980): Competitive Strategy: Techniques for Analyzing Industries and Competitors, New York.

Porter, M. E. (2001): Strategy and the Internet in Harvard Business Review, March, pp. 63 - 78.

Robins, J. A./Wiersema, M. (1999): Strategies for unstructured competitive environments: using scarce resources to create new markets. In: GSM Working Paper, November.

US Department of Commerce (1998): The Emerging Digital Economy, available at http: www.ecommerce.gov. 
M\&K 49. Jahrgang 2/2001

Vogel, H. L. (1999): Entertainment Industry Economics: A Guide for Financial Analysis (4th ed.) New York.

von Krogh, G./Roos, J. (1986): Managing Strategy Processes in Emerging Industries: The Case of Media Firms, London.

Warburg Dillon Read (2000): The Internet in Europe. Global Equity Research. January.

Wolf, M. J. (1999a): The battle for your attention: what entertainment companies must do to profitably capture audiences. In: Strategy and Business, Booz, Allen \& Hamilton, First Quarter, pp. $30-41$.

Wolf, M. J. (1999b) The Entertainment Economy: How Mega-Media Forces are Transforming our Lives. New York. 